\title{
La trampa del bienestar: consumir más produciendo menos
}

Tania Chicaiza Villalba*

\begin{abstract}
Resumen
Las grandes empresas trans y multinacionales dedican importantes sumas de dinero para crear y transmitir mensajes con el fin de alinear a las personas como potenciales consumidores de las marcas que representan sus productos, siendo las responsables de la generación de una cultura de consumo, en su mayoría poco racional, pero que simplemente no se detiene. Esta práctica consumista, en ocasiones muestra una máscara que oculta la verdadera situación económica de un país, y lo que es peor, los auténticos niveles de prosperidad de una sociedad, generando fuertes distorsiones económicas, en donde el bienestar de las futuras generaciones se ve sacrificado por un consumo mediático y no planificado que tiene fuertes externalidades y un gran riesgo de insostenibilidad.
\end{abstract}

\section{Palabras clave}

consumismo - cultura de consumo - situación económica - distorsiones económicas consumo mediático - insostenibilidad económica - círculo vicioso

\begin{abstract}
The multinational corporations spend large amounts of money to create and transmit messages to align people as potential consumers of the brands that represent their products, they have become responsible for the consumer generation culture, quite irrational, but simply can not stop. This practice consumerist, sometimes shows a mask that hides the true financial position of a country, and what is worse, the real levels of prosperity of a society, generating strong economic distortions, where the welfare of future generations is sacrificed for media unplanned consumption that has strong externalities and high risk of unsustainability.
\end{abstract}

\section{Key words}

Consumerism - culture of consumption - economic situation - economic distortions - media consumption - economic unsustainability - vicious circle.

Forma sugerida de citar: Chicaiza Villalba, Tania. 2011. La trampa del bienestar: consumir más produciendo menos. Retos 1. Enero/Junio. Pp. 25-29.

\footnotetext{
* Directora del Área de Ciencias Administrativas y Económicas de la Universidad Politécnica Salesiana. tchicaiza@ups.edu.ec.
}

Retos I(I): 2011 .

(c) 201 I, Universidad Politécnica Salesiana del Ecuador 
Tal situación es agravante en aquellos países, como el nuestro, donde el consumidor está cada vez más expuesto a realizar compras de productos importados, que por ser de 'marca' han encontrado el espacio ideal en los tan difundidos "templos del placer" o más conocidos como centros comerciales, y que se han apropiado de los signos de estatus, prestigio y calidad, en las diferentes versiones de la clase media urbana, siendo estas personas quienes, poco a poco, van desplazando el consumo de lo local, pequeño y poco conocido, por el producto que se muestra global y con despliegues extraordinarios de branding.

La inversión en comunicación persuasiva comercial y la consolidación de redes en los espacios más estratégicos, impacta en el incremento de ventas de productos de consumo, sin que esto traiga consigo una mejora de la calidad de vida y un real desarrollo económico; especialmente para los micro y pequeños negocios que en el caso ecuatoriano son la mayoría, pero el apoderamiento de las franquicias de casi todo espacio comercial, los deja con poco oxígeno para subsistir en este sistema en donde los grandes han copado casi todos los segmentos de mercado.

\section{Una breve exposición de un círculo vicioso}

Sin lugar a dudas, el elevado gasto público en un país, puede ser un gran estimulador de consumo. Pero, si el país no genera garantías económicas y jurídicas suficientes, dicho consumo poco o nada apoya al sector industrial interno, sino que se destina mayoritariamente a la importación de bienes e incluso de servicios como lo son las franquicias.

El gasto público es una pieza fundamental para los análisis sociopolíticos debido a su potencial incidencia en la estructuración y redefiniciones de los modelos de acumulación y de hegemonía (Aponte Blank, 2006).

Ecuador es uno de los pocos países latinoamericanos que, posterior a la crisis, no ha logrado una recuperación económica alta, comparado con lo que ha sucedido con otros de la región. Actualmente, en nuestro país, el ahorro no es atractivo debido a que los bancos tienen excesos de liquidez. Así, los ecuatorianos, han considerado que es preferible la compra de bienes, el incremento de sus activos o patrimonio, optando por el endeudamiento, evitando la inversión, ya sea en bancos o en negocios por los fuertes visos de inseguridad y la falta de garantías que ambos escenarios ofrecen. Un ejemplo claro del tema lo tenemos en el año 2010, la venta de automóviles en el Ecuador alcanzó un año récord y ha presentado un incremento sostenido por varios años; sin embargo, el tráfico y la contaminación han dañado el paisaje de las ciudades más grandes del país. 


\section{Cuando el alto precio del petróleo no es lo mejor}

Estamos experimentando un tercer choque del petróleo. A diferencia de los choques de 1973-1974 y 1979-1980, esta vez la subida de precios se debe al empuje de la demanda, por lo menos en gran parte (Isbell, 2005).

Desde el 2006 los precios del petróleo sufrieron una escalada sin precedentes, llegando en el 2008 a lo más alto de sus récords históricos. Los países productores de petróleo, como Ecuador, han generado a través de su gobierno la expansión del gasto público, en principio para favorecer a los grupos más vulnerables y para mejorar la infraestructura básica del país. Sin embargo, esta política ha resultado, para varios analistas, insuficiente, pues no está acompañada de beneficios y seguridad jurídica a nivel de negocios y empresas, y ha limitado el atractivo del país como destino para la inversión extranjera directa, sobre todo los industriales y agricultores, no han podido atender con su producción nacional a la gran mayoría de habitantes ecuatorianos y más bien se ha evidenciado una constante reducción del sector industrial propio, mientras el consumo sigue en aumento.

Si bien en el discurso resalta la protección a la producción e industria local, se ha tenido que recurrir a las importaciones para evitar el desabastecimiento de todo tipo de bienes.

Retos I ( ): 20 I I.

(C) 201 I, Universidad Politécnica Salesiana del Ecuador
Es así la limitada capacidad productiva del país, ha generado una fuerte presión para el aumento de precios, siendo evidentemente los más afectados en esta situación los consumidores de bajos ingresos. En consecuencia el modelo propuesto los retribuye en el corto plazo pero los perjudica fuertemente en su poder adquisitivo en el mediano y largo plazo.

De ser la salvación para muchos países, el alto precio del petróleo, en el caso ecuatoriano, ha servido para crear burbujas de bienestar económico, con fuertes escaladas de precios, déficit por el aumento de las importaciones, y un dinamismo en los bienes no transables o no exportables como son: la construcción, el comercio y las instituciones financieras, sectores en donde menos mano de obra puede contratarse y donde la diversificación de la misma es limitada.

\section{Un ejemplo del despliegue del consumo: el rol de los centros comerciales}

Como eficiente respuesta al auge del consumo de todo aquello que es importado, aparecen los centros comerciales, cuya dinámica y crecimiento es evidente en el Ecuador.

En un principio los constructores vendían locales comerciales, ahora estos son arrendados, siendo unos pocos constructores los que conservan absoluto control en las operaciones. Al existir un solo dueño, en el centro comercial se imponen horarios, rubros, 
y homogenización de promociones y publicidad. Tomando como ejemplo el caso ecuatoriano, existen aproximadamente 4 grandes empresarios que se han apropiado de los centros comerciales más importantes el país, siendo estos lugares los que han conseguido el alto posicionamiento que tienen hoy en día las marcas internacionales y las franquicias en general y que llegan a contabilizar millones de visitas mensuales con montos de compra siempre crecientes.

El nivel de atracción de los centros comerciales para el común de las personas llega a ser alto, pues se trata de lugares en donde se reúne una diversidad de ofertas de bienes y servicios, sin necesidad de pagar entrada (pero si el servicio del parqueadero) y con la posibilidad de realizar diversas actividades: entretenimiento, distracción, compras, consumo de comida rápida, uso de servicios, pago en bancos, entre otras. Otro factor que ha favorecido su aceptación son porque ofrecen una atención preferencial donde el consumidor se siente cómodo, protegido e identificado con su nivel de vida.

El centro comercial cuenta con una oferta diversificada. La variedad de tipo de establecimientos, en una superficie común, no es ofrecida por otros establecimientos comerciales. Esta diversificación se traduce en la existencia de un gran número de productos y servicios, que le ofrece en distintos estilos de venta, válidos por tanto para distintitas sensibilidades.
El centro comercial aparece para los consumidores como algo más que una superficie de venta. Se convierte en una alternativa lúdica y de ocio, ya que cuenta con otro tipo de establecimientos: cines, bares, discotecas, exposiciones. El consumidor percibe que en centro comercial puede hacer otro tipo de cosas (Gómez Navarro, 1994).

Sin embargo, los beneficios de estos espacios ocultan la realidad del desplazamiento paulatino que tienen las marcas locales, cuya consecuencia es menos empleo diversificado y de aportación tecnológica.

\section{Las franquicias como protagonistas de los centros comerciales}

Al observar el tipo de franquicias predominantes en este tipo de economía, vemos que son precisamente las de alimentos y moda, demostrando la predisposición al gasto por parte de la gente y menoscabando el poder de ahorro.

El sistema de negocios por franquicias que alcanzó un explosivo desarrollo gracias a la globalización de la economía de las naciones orientadas a una creciente apertura en este proceso de transformación del capitalismo. El sistema de franquicias constituye una de las maneras más rápidas y efectivas de la expansión sin necesidad de realizar inversiones de capital y recursos humanos de manera directa. En el Ecuador existen líneas de productos y servicios bajo modalidad de franquicias 
desde hace algunas décadas como Burger King, KFC, entre otras, que constituyen montos de inversión demasiados altos para el denominador común de inversionistas ecuatorianos (Díaz Monar).

Por tanto, en una economía que crece de manera irreal, un repunte en la colocación de franquicias dentro de los centros comerciales, no es precisamente un fuerte indicador de desarrollo.

\section{Conclusiones}

a. El aparato productor industrial y agrícola ecuatoriano se han visto en retrocesos, en medio de una oleada de liquidez que no ha estado acompañada de suficientes estímulos para invertir en la expansión de la industria local.

b. Uno de los sectores con mayor vínculo directo con el consumo de importaciones son los centros comerciales.

c. Varias son las causas por las que se prefiere un centro comercial, pero los altos indicadores de inseguridad contribuyen a que se favorezca a los centros comerciales.

d. Las franquicias en asociación con los espacios y confort de los centros comerciales son el modelo de negocio que se impone como predominante, y son el reflejo de un consumo elevado en alimentos, diversión y moda, que deja descubierto los bajos niveles de ahorro y la susceptibilidad de la economía ante la caída de los precios del petróleo, las crisis financieras y los desastres económicos.

\section{Bibliografía}

\section{Textos}

Isbell, Paul, Los precios del petróleo: la situación actual y perspectivas futuras, Real Instituto Elcano de Estudios Internacionales y Estratégicos, Área: economía y comercio internacional, 2005.

Martínez Felce, Leopoldo, Debates, Instituto de Estudios Superiores de Administración, 2007, Vol 12, Venezuela.

Referencias de internet

Aponte Blank, Carlos, El gasto público social venezolano: sus principales características y cambios recientes desde una perspectiva comparada, Cuadernos del CENDES, Caracas, diciembre 2006, http:/www.scielo.org.ve/ scielo.php?pid=S1012-25082006000300005 $\&$ script $=$ sci_arttext .

Blog de Economía y Finanzas, ‘http://algodeeconomia.blogspot.com/2010/11/inflacion-envenezuela-octubre-2010.html.

Acebedo, Rafael y Mora José, Consideraciones sobre la relación entre la inversión privada y los factores socio-políticos y judiciales en Venezuela y América latina, Compendium; 7/1/2009, Vol. 12 Issue 22, p5-23, 19p, 5 Charts, Biblioteca Virtual privada: http://web.ebscohost.com/ ehost/pdfviewer/pdfviewer?vid=6\& hid $=107 \&$ sid $=96607 \mathrm{c} 78-3978-4 \mathrm{ba} 3-\mathrm{a} 0 \mathrm{a} 7$ ee988c3b43e4\%40sessionmgr113,

Gómez Navarro, Enrique, Centros Comerciales: ventajas competitivas y diseño del futuro, Universidad de Rioja, 1994, 〈http://www. mapa.es/ministerio/pags/biblioteca/revistas/ pdf_DYC/DYC_1994_18_70_80.pdf».

Díaz Monar, Fátima y Flores María Auxiliadora, Las franquicias nacionales en el mercado ecuatoriano: ventajas y desventajas de su aplicación desde el punto de vista del inversionista como del consumidor. http:// repositorio.cladea.org/bitstream/123456789 /186/1/D-27049.pdf>, 〈http://hdl.handle.net/ 123456789/186>

Envío 11 de abril de 2011 - aprobación 26 de abril de 2011 